\title{
RESILIÊNCIA E EXPATRIAÇÃO: DAS ADVERSIDADES À DINÂMICA DO COMPORTAMENTO RESILIENTE DE EXPATRIADOS
}

\author{
RESILIENCE AND EXPATRIATION: ADVERSITIES TO THE DYNAMIC OF RESILIENT BEHAVIOR OF \\ EXPATRIATES
}

\author{
RESILIENCIA Y EXPATRIACIÓN: DE LAS ADVERSIDADES A LA DINÁMICA DEL COMPORTAMIENTO \\ RESILIENTE DE EXPATRIADOS
}

\author{
LAURA ALVES SCHERER \\ Doutoranda \\ Universidade Federal do Pampa - Brasil \\ laurascherer@unipampa.edu.br \\ ITALO FERNANDO MINELLO \\ Doutor \\ Universidade Federal de Santa Maria - Brasil \\ minelloif@gmail.com \\ Submetido em: 27/06/2017 \\ Aprovado em: 13/09/2017
}

Doi: alcance.v24n3.p329-349

\section{RESUMO}

A resiliência consiste em um processo dinâmico em que um indivíduo, ao vivenciar uma adversidade, busca enfrentar e se adaptar, como pode ocorrer com expatriados que vivenciam situações de estresse ao irem para outro país. Assim, este artigo tem como objetivo analisar o comportamento resiliente de brasileiros expatriados na China diante da experiência de expatriação. Trata-se de uma pesquisa qualitativa e exploratória. Foram realizadas entrevistas semiestruturadas com doze expatriados brasileiros na China, as quais foram analisadas sob a luz da técnica de análise de conteúdo. As categorias definidas a priori foram: situações de adversidade e dinâmica do comportamento resiliente. Como resultados, destaca-se que a maioria das adversidades estava relacionada a aspectos pertencentes à cultura do país de expatriação. Em um primeiro momento a reação espontânea dos expatriados era a negação e, com o tempo, a aceitação, culminando no sentimento de adaptação durante esta experiência. Ressalta-se a oscilação entre momentos de estabilidade emocional e momentos de angústia e isolamento. Este fato vai ao encontro da curva de adaptação e aculturação do expatriado, que demonstra o movimento dos sentimentos e comportamento do indivíduo no estrangeiro, o que pode ser relacionado à dinamicidade do comportamento resiliente dos expatriados, ora positivo, ora negativo.

Palavras-chave: resiliência; comportamento resiliente; expatriação.

\section{ABSTRACT}

Resilience is a dynamic process in which an individual experiencing an adversity seeks to face it and adapt to it, as can occur with expatriates experiencing stressful situations when they travel to another country. This article analyzes the resilient behavior of expatriate Brazilians in China in the face of the expatriation experience. This is a qualitative and exploratory research. Semi-structured interviews were conducted with twelve Brazilian expatriates in China, which were then analyzed using the technique of content analysis. The categories defined a priori were: situations of adversity and dynamics of resilient behavior. The results highlighted that most of the adversities were related to aspects related to the culture of the expatriation country. At first the spontaneous reaction of the expatriates was denial, and with time, acceptance, culminating in a feeling of adaptation during this experience. There was also fluctuation between moments of emotional stability and moments of anguish and isolation. This fact 
is in line with the expatriate adaptation and acculturation curve, which demonstrates shifts in the individual's feelings and behavior abroad. These, in turn, may be related to the dynamics of resilient behavior of expatriates, i.e. sometimes positive, sometimes negative.

Keywords: resilience, resilient behavior; expatriation

\section{RESUMEN}

La resiliencia consiste en un proceso dinámico en el que un individuo, al experienciar una adversidad, intenta afrontarla y adaptarse, como puede ocurrir con expatriados que vivencian situaciones de estrés al ir a otro país. Este artículo tiene como objetivo analizar el comportamiento resiliente de brasileños expatriados en China ante la experiencia de expatriación. Se trata de una investigación cualitativa y exploratoria. Se realizaron entrevistas semiestructuradas con doce expatriados brasileños en China, las cuales fueron analizadas con la técnica de análisis de contenido. Las categorías definidas a priori fueron: situaciones de adversidad y dinámica del comportamiento resiliente. Como resultados, se destaca que la mayoría de las adversidades estaban relacionadas con aspectos de la cultura del país de expatriación. La primera reacción de los expatriados era la negación, y después, la aceptación, culminando en el sentimiento de adaptación durante esta experiencia. Se resalta la oscilación entre momentos de estabilidad emocional y momentos de angustia y aislamiento. Este hecho va al encuentro de la curva de adaptación y aculturación del expatriado, que demuestra el movimiento de los sentimientos y comportamiento del individuo en el extranjero, lo que puede ser relacionado con la dinamicidad del comportamiento resiliente de los expatriados, a veces positivo y otras negativo.

Palabras clave: Resiliencia; Comportamiento resiliente; Expatriación.

\section{INTRODUÇÃO}

Nas últimas décadas, há um interesse na academia por compreender o fenômeno da expatriação, sendo este um dos temas mais explorados em estudos de gestão internacional de recursos humanos (STAHL; CALIGIURI, 2005; MOTT et al., 2012; SILVA et al., 2013). Dentre as temáticas de pesquisa relacionadas ao expatriado, pode-se citar políticas e processos, remuneração, cargo, salários, treinamento, transferência de conhecimento de matriz para subsidiária, dentre outros (ORSI, 2010; WANG et al., 2009; SILVA et al., 2013). E em relação aos aspectos voltados para o comportamento do expatriado, destacam-se estudos relacionados às competências; à cultura; ao gênero; ao ajustamento; à adaptação de seus filhos, cônjuge e do próprio expatriado; aos repatriados; dentre outros (BLACK; MENDENHALL, 1991; CALIGIURI, 2000; STAHL; CALIGIURI, 2005; SILVA et al., 2013).

No que diz respeito aos aspectos do comportamento do indivíduo expatriado, é importante ressaltar que a expatriação leva o indivíduo a conviver com situações distintas do seu habitual, o que pode gerar situações de estresse e provocar alterações em seu comportamento. Dependendo como o expatriado lida com essas situações, pode afetar o seu desempenho na empresa e até mesmo a sua permanência no país destino. Alguns autores (HOFSTEDE, 1991; STAHL; CALIGIURI, 2005; FROESE; PELTOKORPI, 2011) evidenciam que a desistência da expatriação é um problema comum das empresas que enviam seus funcionários para o exterior. Os motivos que levam a esse retorno prematuro do expatriado para a sua terra natal geralmente estão associados à sua dificuldade de adaptação ou de seu cônjuge.

Nesse contexto, o conceito de resiliência parece adquirir especial importância, pois de acordo com Rutter (2012) e Masten e Cicchetti (2016), a resiliência consiste na capacidade de um sistema dinâmico de um indivíduo suportar ou se adaptar a desafios significativos que ameaçam a sua estabilidade, a sua viabilidade ou o seu desenvolvimento. Embora a resiliência tenha sua origem no campo da física e da engenharia (GOLDSCHMIDT; IRIGARAY, 2016), também é investigado na educação, na enfermagem, na psicologia, na psiquiatria (ARMSTRONG et al., 2011; DICORCIA; TRONICK, 2011; RUTTER, 2012; LUTHAR et al., 2014; MASTEN; CICHETTI, 2016), dentre outros e mais recentemente na administração (COUTU, 2002; BARLACH et al., 2008; MINELLO; SCHERER; ALVES, 2012; CANTONI; GIUSTINIANO, 2015; MINELLO, 2014). A resiliência, nos estudos de Administração, "surge como produto da interação entre o sujeito ou o sistema e o meio em que está inserido" (GOLDSCHMIDT; IRIGARAY, 2016, p. 2). É no trabalho nas organizações que o comportamento 
resiliente pode ser 0 componente diferencial entre 0 enfrentamento da situação que leva ao crescimento psicológico ou a sensação de vitimização, de transformação de crises em oportunidades (BARLACH et al., 2008).

Diante disso, surgem temáticas que buscam compreender o comportamento do expatriado no país destino e a resiliência é uma delas. Orsi (2010) destaca a resiliência como uma habilidade necessária ao cotidiano do expatriado. Nesta mesma linha, Minello, Scherer e Alves (2012) argumentam que a resiliência pode ser considerada uma competência, o que vai ao encontro com a ideia de Caligiuri e Tarique (2012) que afirmam que uma das preocupações da gestão internacional de empresas é reter profissionais com competências interculturais, capazes de lidar com a diversidade.

No caso dos expatriados, diversas competências são necessárias para viver e trabalhar em um ambiente distinto do seu. Ressalta-se que a resiliência é um construto que vem sendo investigado na área de desenvolvimento humano e vem ganhando cada vez mais espaço na área de recursos humanos, tendo em vista a sua importância para os indivíduos nas organizações (INFANTE, 2005). Cantoni e Giustiniano (2015) argumentam que a gestão de recursos humanos de uma organização pode contribuir para que seus funcionários em mobilidade internacional desenvolvam a resiliência, ao tentar antecipar problemas que podem ocorrer com 0 indivíduo, a matriz e a subsidiária.

Com base no exposto até então, sinaliza-se que o comportamento resiliente emerge a partir de situações estressoras (RUTTER, 2012; LUTHAR et al., 2014), o que pode ser relacionado à experiência vivenciada por expatriados que, ao serem enviados para outros países, se deparam com situações de estresse em âmbitos profissional e pessoal, que por sua vez evidenciam seu comportamento resiliente. Estas situações podem ser observadas, especialmente quando se está em um país distante culturalmente, como é o caso de brasileiros na China, unidades de análise deste estudo. Nesse sentido, o objetivo desta pesquisa é analisar o comportamento resiliente de brasileiros expatriados na China diante da experiência de expatriação.

\section{RESILIÊNCIA COMO UM PROCESSO DINÂMICO}

A interação do indivíduo com o meio envolve diferentes aspectos que, no momento em que interagem mutuamente, também representam um processo, que culmina no comportamento desse indivíduo, portanto, resultante dessa interação. Esse raciocínio apresenta coerência em relação à adoção do conceito de resiliência como um processo de Grotberg (2005) para este estudo. Nesse sentido, no intuito de ilustrar este enfoque, resgatase a ideia de que a resiliência já foi categorizada como um traço pessoal, inerente ao indivíduo. Porém, poucos autores ainda insistem nessa abordagem, pois a visão predominante é de tratar o fenômeno como um processo dinâmico, multidimensional ou ecossistêmico (BARLACH et al., 2008; MASTEN, 2011; RUTTER, 2012; LUTHAR et al., 2014; GOLDSCHMIDT; IRIGARAY, 2016; MASTEN; CICCHETTI, 2016).

Para Grotberg (2005, p.15), resiliência é "a capacidade humana para enfrentar, vencer e ser fortalecido ou transformado por experiências de adversidade". No intuito de ampliar o conhecimento sobre o tema, a autora, que tem como base dos resultados de seus estudos o Projeto Internacional de Resiliência, evidenciou novas descobertas que agregam ao construto da resiliência a perspectiva de processo. A partir dessa pesquisa, a autora sugere a ideia de que a resiliência pode ser considerada como um processo composto por (i) fatores, (ii) comportamentos e (iii) resultados resilientes.

Os fatores resilientes estão relacionados ao crescimento e ao desenvolvimento humano, incluindo diferenças de idade e gênero, e estão organizados em quatro categorias (Figura 1).

Figura 1: Fatores resilientes

\section{Eu tenho (apoio)}

Pessoas do entorno em quem confio e que me querem incondicionalmente;

Pessoas que me põem limites para que eu aprenda a evitar os perigos ou os problemas;

Pessoas que me mostram, por meio da sua conduta, a maneira correta de proceder;

Pessoas que querem que eu aprenda a me desenvolver sozinho;

Pessoas que me ajudam quando estou doente, ou em perigo, ou quando necessito aprender.

(continuação...) 


\begin{tabular}{|ll|}
\hline \multicolumn{1}{c|}{ Eu sou (relativo ao desenvolvimento da força intrapsíquica) } \\
\hline$\checkmark$ & Uma pessoa pela qual os outros sentem apreço e carinho; \\
$\checkmark$ & Feliz quando faço algo bom para os outros e lhes demonstro meu afeto; \\
$\checkmark$ & Respeitoso comigo mesmo e com o próximo. \\
\hline \multicolumn{1}{c|}{ Eu estou (relativo ao desenvolvimento da força intrapsíquica) } \\
\hline$\checkmark$ & Disposto a me responsabilizar por meus atos; \\
\hline \multicolumn{2}{c|}{ Eu posso (aquisição de habilidades interpessoais e resolução de conflitos) } \\
\hline$\checkmark$ & Falar sobre coisas que me assustam ou inquietam; \\
$\checkmark$ & Procurar a maneira de resolver os problemas; \\
$\checkmark$ & Controlar-me quando tenho vontade de fazer algo errado ou perigoso; \\
$\checkmark$ & Encontrar alguém que me ajude quando necessito.
\end{tabular}

Fonte: Elaborada pelos autores com base em Grotberg (2005).

Esses fatores supõem uma interação dinâmica e podem ir mudando conforme a etapa de desenvolvimento, pois as situações de adversidade não são estáticas e requerem mudanças. Isto requer se preparar, viver e aprender com as experiências diversas, como uma mudança de país (GROTBERG, 2005). Cantoni e Giustiniano (2015) reforçam esta ideia ao sustentar que a mobilidade internacional, no caso de trabalho no exterior, demanda resiliência dos funcionários, sendo papel da organização estar atenta para auxiliar neste processo.

O comportamento resiliente, por sua vez, pressupõe a dinamicidade dos referidos fatores de resiliência para enfrentar a adversidade. Os passos incluem a sequência de identificar a adversidade, definindo as causas e os riscos dos problemas, e selecionar o nível e o tipo de resposta adequados, pois dependendo do tipo de adversidade pode-se ter uma reação imediata (ex.: assalto, morte de pessoa querida) ou, então, pode-se ter mais tempo para pensar na melhor alternativa (ex.: mudança, divórcio). Da mesma forma que uma adversidade, para um indivíduo pode ser excessiva ou traumática, para outro pode ser leve (GROTBERG, 2005). Armstrong et al. (2011) complementam que, frente a eventos negativos, a inteligência emocional ajuda a selecionar a resposta adequada que culmina no comportamento resiliente.

No que se refere aos resultados resilientes, segundo Grotberg (2005), o objetivo da resiliência não é só enfrentar a adversidade, mas também se beneficiar das experiências. Alguns desses benefícios podem ser aprender com a experiência; estimar o impacto sobre os outros, no sentido de não prejudicar ninguém ao enfrentar a adversidade e manter o respeito pelos outros e por si mesmo; e reconhecer um crescimento, no sentido de bemestar e melhoria da qualidade de vida, o que pressupõe saúde mental e emocional. A estabilidade emocional permite ao indivíduo criar resistência e uma probabilidade de avaliar as situações futuras de maneira mais otimista, é a capacidade de perceber que é possível lidar com isso (SEERY et al., 2010).

Tendo em vista as definições apresentadas e considerando o conceito adotado para este estudo da resiliência como um processo dinâmico (GROTBERG, 2005), pode-se constatar a relação de influência do comportamento resiliente sobre a resiliência. Dessa forma, partindo desse conceito de resiliência evidencia-se que o comportamento resiliente é o movimento dentro do processo da resiliência (MINELLO, 2014), o qual se caracteriza pela adversidade ou estresse e pela capacidade adaptativa.

De acordo com Minello (2014), esse movimento parte da resiliência original de cada indivíduo e, ao longo do tempo, vai se alterando em função das diferentes situações pelas quais o sujeito passa; como no caso da expatriação. Isto pode "gerar comportamentos resilientes mais ou menos eficientes, rupturas da resiliência original e pode culminar em comportamentos resilientes positivos ou negativos" (MINELLO, 2014, p. 51). Percebe-se, então, que a dinamicidade do comportamento resiliente influencia a própria resiliência do indivíduo. Para Minello (2014), essa dinamicidade depende da presença ou da ausência de estímulos sociais, suporte emocional, familiar ou de pessoas próximas; fatores que levam a um comportamento resiliente positivo ou negativo.

- Comportamento resiliente positivo - o indivíduo tem condições de buscar ampliação da sua capacidade de adaptação e de recuperação, por meio de ações como buscar aprender com experiências passadas, buscar conhecimento, entre outras.

- Comportamento resiliente negativo - o indivíduo não tem condições de se recuperar totalmente do impacto do estressor. Comportamentos adaptativos cognitivos demoram mais tempo para serem atingidos. 
Geralmente este momento está associado a retraimento social e estágios emocionais adaptativos equivalentes aos encontrados no período de luto.

A maioria dos estudos de resiliência traz a abordagem do comportamento resiliente positivo, sobre 0 indivíduo que superou alguma adversidade. Em contraposição, o comportamento resiliente negativo é menos mencionado na teoria, pois se refere ao fato do indivíduo não conseguir utilizar seus fatores resilientes para lidar com a adversidade, ou utilizar estratégias de enfrentamento e falhar, ou levar um tempo maior para se recuperar.

Minello (2014) aborda sobre as situações em que o indivíduo não consegue suportar as pressões provocadas pela adversidade. A situação adversa provoca um processo de ruptura no status quo do ser humano, gerando uma série de dificuldades, conflitos, dúvidas que influenciam nas atividades do cotidiano do sujeito, o que pode trazer reflexos importantes na sua saúde física e psíquica (SATO, 1993). DiCorcia e Tronick (2011) e Masten e Cicchetti (2016) alertam que essas situações não necessariamente são catástrofes, mas situações do cotidiano que provocam estresse e, consequentemente, desestabilizam o ser humano. Para Bergamini (2005), o esforço para alcançar soluções pode provocar desgaste psicológico e redução de energia, proporcionando uma pressão, gerando apatia, perda de motivação, estresse, depressão - ou no caso dos expatriados, poderia ocasionar a desistência da atividade no exterior, retornando ao seu país natal.

Frente ao exposto, percebe-se que o comportamento resiliente apresenta uma característica dinâmica, ou seja, ao enfrentar uma adversidade, ou uma série de estressores, não significa que o indivíduo vai apresentar um comportamento estático, de ser resiliente ou não. Dependendo do estressor, do contexto e do momento em que o indivíduo se encontra, ora o seu comportamento resiliente pode ser positivo, ora negativo.

\section{CARACTERÍSTICAS E DESAFIOS DO EXPATRIADO}

O expatriado tem por definição o profissional enviado por uma empresa para uma unidade relacionada em um país estrangeiro para realizar um trabalho específico ou cumprir um objetivo relacionado à organização (CALIGIURI, 2000; FROESE; PELTOKORPI, 2011). Outro tipo de expatriado, mencionado por Froese e Peltokorpi (2011), trata-se do autoexpatriado, em que a opção de trabalhar no exterior é uma iniciativa própria, a fim de buscar desenvolvimento pessoal. A literatura aponta que o período de permanência no exterior pode variar. Caliguiri (2000), por exemplo, menciona o tempo mínimo de dois anos, já Edström e Galbraith (1977) consideram que 0 período de tempo de expatriação está geralmente pré-designado entre seis meses a cinco anos. Para assumir este compromisso de trabalhar no exterior, algumas características são requeridas para que estes profissionais vivenciem uma experiência bem-sucedida.

Shaffer et al. (2006) e Caligiuri e Tarique (2012) consideram a necessidade de competências para a efetividade da expatriação. No estudo de Shaffer et al. (2006) são considerados dois tipos de competências: estáveis e dinâmicas. Como competências estáveis, os autores mencionam que o profissional deve ter consciência em relação a ser cuidadoso; ter disciplina; ter estabilidade emocional, que é a tendência de reagir positivamente e calmamente a eventos estressantes; tendência de ter bom relacionamento interpessoal; estar aberto para novas experiências; ser original; inovador; correr riscos; ser extrovertido no seu modo de se expressar e se comportar. Como competências dinâmicas, os autores mencionam a flexibilidade cultural, que é a capacidade de substituir as atividades que costumam fazer no seu país de origem, por outras habituais do local onde ele estão; ter envolvimento e motivação para alcançar os objetivos da empresa e se relacionar com os colegas; entender que os padrões culturais do país de destino não são melhores nem piores que os do seu. As características que compõem estas competências referidas por Shaffer et al. (2006) podem ser relacionadas à definição de resiliência proposta por Grotberg (2005), que por sua vez vai ao encontro da ideia de Caligiuri (2000) e Orsi (2010), que consideram a resiliência como uma característica necessária ao expatriado bem-sucedido.

Embora o profissional atenda à maioria das competências necessárias, pesquisas (HOFSTEDE, 1991; STAHL; CALIGIURI, 2005; NUNES et al., 2008; MURITIBA et al., 2010; FONSECA, 2011; FROESE; PELTOKORPI, 2011; MOTT et al., 2013; SILVA et al., 2013; GALLON; SCHEFFER, 2015; ZWIELEWSKI; TOLFO, 2016) revelam que os expatriados podem ter algumas dificuldades na adaptação do trabalho por causa da distância cultural entre países, que podem prejudicar a sua satisfação no trabalho. Colie et al. (2010) e Van Erp et al. (2011) estão em consonância com esta afirmativa e acrescentam que a atividade internacional vai acarretar discordâncias interpessoais na empresa e na vida pessoal, pois determinados pontos de vista não fazem parte do modelo mental do expatriado. Inclusive Gallon e Scheffer (2015) argumentam que a dificuldade de adaptação

Revista Alcance - Eletrônica - vol. 24 - n. 3 - jul./set. 2017 
adquire uma dimensão tamanha na vida dos expatriados, que as preocupações em relação à carreira e ao crescimento profissional, frequentemente, são relegadas a segundo plano.

Uma teoria que explica esse cenário é relativa à curva de adaptação, analisada por diferentes pesquisadores (HOFSTEDE, 1991; BLACK; MENDENHALL, 1991; CERDIN, 2002, apud NUNES et al., 2008). Estes estudos trazem muitos pontos em comum, dentre os quais relacionam as fases de adaptação do processo de expatriação em função do tempo de permanência no país estrangeiro. Esta sistematização é elaborada em formato de gráfico, sendo que neste estudo é apresentado na Figura 2 o gráfico da curva de aculturação de Hofstede (1991), por apresentar uma peculiaridade em sua quarta fase, que se relaciona com o processo dinâmico da resiliência. Estes autores que teorizaram a curva ressaltam a importância de se compreender o modelo empiricamente, pois cada indivíduo possui suas particularidades, assim como, dependendo do país, as reações são mais ou menos problemáticas para os indivíduos.

Figura 2: Curva de aculturação

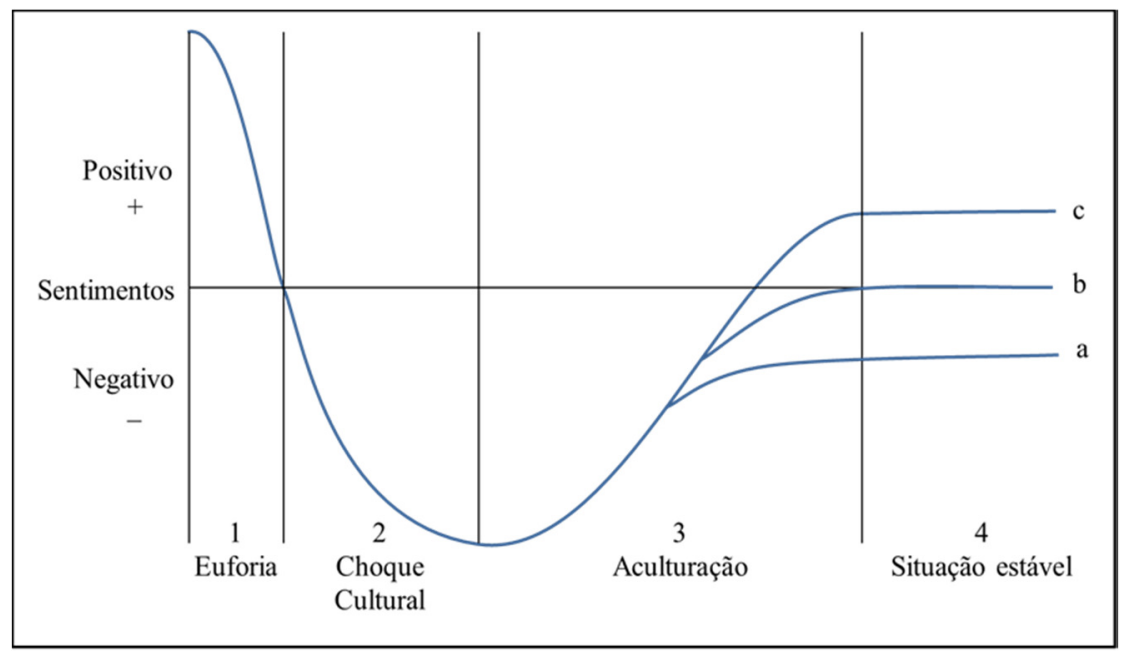

Fonte: Hofstede (1991).

São quatro as fases expostas na Figura 2. A primeira delas é a Euforia - quando se dá a fascinação, a alegria, a excitação pelo novo país; a lua de mel, a emoção de viajar e de ver novas terras. A segunda é o Choque Cultural - marcado pela desilusão e frustração; um período mais difícil, associado a dilemas com a vida no exterior; quando começa a vida real no novo ambiente. A fase seguinte é a Aculturação - ajustamento gradual à nova cultura; inicia-se quando o visitante aprendeu gradualmente a funcionar nas novas condições, adotou alguns valores locais, adquiriu confiança em si próprio e integrou-se na nova rede social. $E$ a quarta fase é a Situação Estável - crescimento, fortalecimento da capacidade do indivíduo em funcionar eficazmente na nova cultura; estado de estabilidade mental que finalmente se alcança.

Esta última fase apresenta uma peculiaridade: as letras "a, b, c" ilustram que podem haver variações na estabilidade do estrangeiro. A letra "a" representa que os sentimentos podem permanecer negativos em comparação com a cultura de origem, por exemplo, se o estrangeiro ainda se sente um estranho ou discriminado. A letra "b" representa o sentimento de sentir-se igualmente tão bem quanto antes e, nesse caso, pode-se considerar que o visitante conseguiu uma adaptação bicultural. E a letra "c" representa que o estrangeiro se sente melhor ainda, que se adaptou totalmente ao modo de vida de seus anfitriões (HOFSTEDE, 1991). Essas variações indicam que 0 ajustamento cultural não se dá da mesma forma para todas as pessoas, mesmo que elas apresentem características semelhantes e tenham como partida e chegada lugares em comum. Quando um expatriado vai para outro país, ele não sabe exatamente o que esperar e como se comportar na cultura anfitriã, sendo que vários podem ser os elementos que dificultam sua adaptação.

Pode-se tomar como exemplo as diferenças de idioma, que na pesquisa de Pimentel (2009) e Muritiba et al. (2010), foi mencionado (o idioma) como a principal barreira para os brasileiros fazerem negócios no exterior, seguido das questões políticas, econômicas e de legislação, que podem dificultar o dia a dia das operações na organização no estrangeiro. Para Gallon e Scheffer (2015), compreender o idioma do país estrangeiro, dentre 
outros aspectos culturais, é uma preocupação que antecede às questões profissionais. Outro aspecto importante diz respeito à religião. Muritiba e Albuquerque (2009) e Zwielewski e Tolfo (2016) afirmam que, em alguns países, a crença religiosa dita o comportamento e os costumes da sociedade, o que pode ter influência no modo de fazer negócios.

Uma dificuldade encontrada na pesquisa com franceses no Brasil, segundo Freitas (2010), foi a adaptação da esposa e dos filhos de homens expatriados, que ficam sozinhos, enquanto o pai se ocupa com a empresa. A mãe, que se sente insegura e fragilizada, tem que ser forte para dar suporte para os filhos (FREITAS, 2010). Estes tipos de dificuldades podem levar a desentendimentos nos negócios, ansiedade, depressão, além de desafios à unidade familiar (MURITIBA; ALBUQUERQUE, 2009; GALLON; SCHEFFER, 2015). Em situações mais extremas, pode-se considerar a desistência prematura da expatriação, o que não é decisão difícil de acontecer (HOFSTEDE, 1991; STAHL; CALIGIURI, 2005; FROESE; PELTOKORPI, 2011). Para Stahl e Caligiuri (2005), o desejo de querer ficar no país está relacionado à atividade exercida e ao seu tempo de duração. Quanto maior o período que 0 expatriado sabe que deve permanecer no país anfitrião, mais ele vai procurar se adaptar à cultura e atender às necessidades e às exigências para o cumprimento de sua atividade.

Como forma de minimizar estes fatores, é sugerida a realização de treinamentos e informações sobre os aspectos culturais e características de personalidade tanto para o expatriado como para os funcionários da unidade local (ORSI, 2010; SILVA et al., 2013). Uma maior consciência das diferenças culturais nas interações de trabalho e estilos de liderança diminui mal-entendidos e estereótipos negativos (FROESE; PELTOKORPI, 2011). Cabe salientar que, antes de tudo, a seleção dos expatriados deve ser criteriosa, a fim de minimizar dificuldades de adaptação. Muritiba e Albuquerque (2009) destacam sete critérios que devem compor o perfil do profissional internacional: experiência internacional, habilidades interpessoais, experiência no país, habilidades com idiomas, flexibilidade familiar, experiência profissional e competência técnica. Além disso, corroborando com esta ideia, o expatriado de hoje já deve ter uma noção do tipo de dificuldade que irá enfrentar, pois para ser escolhido para assumir a vaga no exterior, é visto como positivo já ter domínio e experiência em outras culturas (STEGER et al., 2011).

Outra forma de minimizar as dificuldades é o acompanhamento da família. A família atua como um apoio ao expatriado, auxiliando a assimilar o comportamento social e as normas do país estrangeiro (MACHADO; HERNANDES, 2004; FREITAS, 2010). Van Erp et al. (2011) também consideram importante esse aspecto, pois 0 ajustamento cultural do expatriado depende do ajustamento cultural do cônjuge, aspecto que deve ser considerado pelas empresas no momento de seleção. Nesse sentido, o cônjuge do expatriado consiste em um papel importante no processo de expatriação, pois ele é envolvido desde o início dos procedimentos de preparação. Estes autores enfatizam também a importância da relação do casal, pois a rotina muda e a adaptação vai depender de como eles lidam com essas novidades.

A busca por esse ajustamento parece estar atrelada aos aspectos culturais do ambiente em que o indivíduo está inserido. Nesse sentido, um dos fatores que contribui para a adaptação do profissional expatriado é a compreensão dos traços culturais em âmbitos organizacional e nacional do país para o qual o mesmo será enviado.

\section{CAMINHO METODOLÓGICO}

Com o objetivo de analisar o comportamento resiliente de brasileiros expatriados na China, este artigo adota uma abordagem qualitativa, do tipo exploratória. Para Richardson (2011), a pesquisa qualitativa analisa situações complexas e particulares, a fim de compreender processos dinâmicos vividos por grupos sociais e possibilitar, em nível de profundidade, o entendimento das particularidades do comportamento dos indivíduos, 0 que parece ser coerente em relação ao proposto por esta pesquisa. No que se refere ao caráter exploratório, segundo Sampieri et al. (2006), este tipo de estudo busca discutir e avançar no conhecimento sobre temas ainda pouco pesquisados e/ou ainda ampliar estudos já existentes a partir de novas perspectivas. Levando-se em consideração o objetivo deste artigo, enfatiza-se que a relação entre os temas resiliência e expatriação ainda é pouco explorada na literatura sobre o tema, o que demonstra a adequação deste tipo de pesquisa para o presente estudo.

A coleta de dados foi feita por meio de entrevistas semiestruturadas, a partir de um roteiro de entrevista previamente definido, com doze profissionais brasileiros expatriados na China. Os indivíduos participantes da pesquisa são chamados de unidades de análise, em vez de amostra, pois não se tem a pretensão de generalização

Revista Alcance - Eletrônica - vol. 24 - n. 3 - jul./set. 2017 
dos resultados, e sim a profundidade na análise (RICHARDSON, 2011), sobre o comportamento dos referidos expatriados diante da experiência de expatriação. Adotou-se como critério para a definição da unidade de análise o profissional brasileiro que foi trabalhar em um mesmo país estrangeiro, a China, enviado por uma empresa ou por iniciativa própria, por um período mínimo de seis meses.

Para se contatar os participantes, utilizaram-se as técnicas: purposeful sampling e bola de neve. Na visão de Glesne (1990), citado por Eriksson e Kovalainen (2008), a purposeful sampling significa ser possível utilizar diversas fontes de informação, como as utilizadas neste estudo: redes sociais virtuais e indicações. A partir do contato com o primeiro entrevistado, que foi indicado por um professor durante um evento acadêmico e contatado via Facebook, iniciou-se a técnica da bola de neve, em que o participante indica outras pessoas que se enquadrem nos critérios da pesquisa (PATTON, 1990 apud ERIKSSON; KOVALAINEN, 2008). As demais indicações foram contatadas por e-mail, celular, Facebook e Skype. A cada contato, um e-mail com a explicação dos objetivos da pesquisa era enviado, bem como era solicitada a autorização para gravação da entrevista em áudio. O perfil dos entrevistados pode ser visualizado na Figura 3.

Figura 3: Perfil dos Expatriados Entrevistados

\begin{tabular}{|c|c|c|c|c|c|c|c|}
\hline 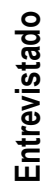 & 옳 & $\begin{array}{l}\frac{0}{0} \\
\text { 응 }\end{array}$ & $\begin{array}{l}\frac{0}{0} \\
\frac{\pi}{0} \\
\frac{0}{\pi} \\
\frac{\pi}{2} \\
\frac{\pi}{2}\end{array}$ & Formação & $\begin{array}{l}\text { Área de } \\
\text { atuação da } \\
\text { empresa }\end{array}$ & $\begin{array}{l}\text { Cargos/ } \\
\text { Funções na } \\
\text { China }\end{array}$ & $\begin{array}{c}\text { Tempo de } \\
\text { expatriação }\end{array}$ \\
\hline E1 & $\mathrm{F}$ & 21 & RS & Jornalismo incompleto & Moda & $\begin{array}{l}\text { Modelo de } \\
\text { Agência e free- } \\
\text { lancer }\end{array}$ & $\begin{array}{c}7 \text { meses }+4 \\
\text { meses até o } \\
\text { momento da } \\
\text { pesquisa }\end{array}$ \\
\hline E2 & $\mathrm{F}$ & 38 & SP & $\begin{array}{l}\text { Comércio Exterior; } \\
\text { Espec. em Marketing }\end{array}$ & Iluminação & $\begin{array}{c}\text { Diretora de } \\
\text { Marketing da } \\
\text { Ásia e depois só } \\
\text { da China }\end{array}$ & $\begin{array}{c}3 \text { anos e } 4 \text { meses } \\
\text { até o momento da } \\
\text { pesquisa }\end{array}$ \\
\hline E3 & $M$ & 45 & RS & $\begin{array}{l}\text { Engenharia Elétrica; } \\
\text { Espec. em Engenharia } \\
\text { de Segurança do } \\
\text { Trabalho e MBA }\end{array}$ & $\begin{array}{l}\text { Equipamen-tos } \\
\text { para o ramo } \\
\text { de energia }\end{array}$ & $\begin{array}{l}\text { Gerente de } \\
\text { Produção, } \\
\text { Diretor } \\
\text { Industrial, } \\
\text { Diretor Geral }\end{array}$ & 7 anos \\
\hline E4 & $\mathrm{F}$ & 21 & CE & $\begin{array}{c}\text { Publicidade e } \\
\text { Propaganda incompleto }\end{array}$ & Moda & $\begin{array}{l}\text { Modelo de } \\
\text { Agência }\end{array}$ & $\begin{array}{c}3 \text { meses }+3 \\
\text { meses }+3 \text { meses }\end{array}$ \\
\hline E5 & M & 43 & RJ & $\begin{array}{c}\text { Administração de } \\
\text { Empresas }\end{array}$ & Alimentos & Gerente Geral & $\begin{array}{c}2 \text { anos até o } \\
\text { momento da } \\
\text { pesquisa }\end{array}$ \\
\hline E6 & $\mathrm{F}$ & 40 & SP & $\begin{array}{l}\text { Letras e Pós-Graduação } \\
\text { em Literatura }\end{array}$ & Alimentos & $\begin{array}{c}\text { Coordenadora de } \\
\text { Administração de } \\
\text { Vendas } \\
\end{array}$ & $\begin{array}{c}1 \text { ano e } 7 \text { meses } \\
\text { até o momento da } \\
\text { pesquisa }\end{array}$ \\
\hline E7 & $\mathrm{F}$ & 30 & SP & Arquitetura & Arquitetura & Arquiteta Sênior & 3 anos e meio \\
\hline E8 & M & 27 & CE & $\begin{array}{l}\text { Engenharia Mecânica } \\
\text { de Aeronáutica }\end{array}$ & Intercâmbios & $\begin{array}{l}\text { Vice-Presidente } \\
\text { de Relações } \\
\text { Sociais } \\
\text { Corporativas }\end{array}$ & 7 meses \\
\hline E9 & M & 32 & RS & $\begin{array}{c}\text { Administração de } \\
\text { Empresas e MBA em } \\
\text { Logística Empresarial e } \\
\text { Coaching Profissional }\end{array}$ & $\begin{array}{l}\text { Autopeças da } \\
\text { linha pesada }\end{array}$ & $\begin{array}{l}\text { Coordenador de } \\
\text { Supply Chain }\end{array}$ & 8 meses \\
\hline
\end{tabular}

(Continuação...) 
Figura 3: Perfil dos Expatriados Entrevistados

\begin{tabular}{|c|c|c|c|c|c|c|c|}
\hline E10 & M & 47 & RS & $\begin{array}{c}\text { Ensino Médio e } \\
\text { Cursos } \\
\text { Profissionalizantes na } \\
\text { área de calçado, couro } \\
\text { e afins }\end{array}$ & Calçadista & $\begin{array}{c}\text { Técnico em } \\
\text { calçados }\end{array}$ & $\begin{array}{c}8 \text { anos até o } \\
\text { momento da } \\
\text { pesquisa }\end{array}$ \\
\hline E11 & M & 26 & RN & $\begin{array}{c}\text { Segurança na Inglaterra } \\
\text { e Téc. de Segurança no } \\
\text { Brasil }\end{array}$ & $\begin{array}{c}\text { Segurança, } \\
\text { Meio } \\
\text { Ambiente e } \\
\text { Saúde }\end{array}$ & $\begin{array}{c}\text { Analista de } \\
\text { Qualidade } \\
\text { Segurança, } \\
\text { Meio Ambiente e } \\
\text { Saúde }\end{array}$ & 1 ano e 6 meses \\
\hline E12 & M & 30 & RS & $\begin{array}{c}\text { Automação Industrial, } \\
\text { Mestrado em Eng.de } \\
\text { Materiais, MBA em } \\
\text { Gestão Empresarial e } \\
\text { em Negócios } \\
\text { Internacionais com a } \\
\text { China }\end{array}$ & $\begin{array}{c}\text { Veículos } \\
\text { comerciais de } \\
\text { transporte de } \\
\text { cargas }\end{array}$ & $\begin{array}{c}\text { Analista de } \\
\text { desenvolvi-mento } \\
\text { de fornecedores } \\
\text { para o Grupo de } \\
\text { empresas }\end{array}$ & $\begin{array}{c}6 \text { meses }+1 \text { ano } \\
\text { até o momento da } \\
\text { pesquisa }\end{array}$ \\
\hline
\end{tabular}

Fonte: Elaborada pelos autores.

Os expatriados entrevistados, em sua maioria, foram enviados para a China pela empresa brasileira em que trabalhavam, com exceção dos entrevistados E7, E8 e E10, que foram por iniciativa própria, porém já tinham o contato prévio com a empresa que iriam trabalhar. Para E3, E4, E5, E8 e E10, ir trabalhar na China se configura sua primeira expatriação. Os demais já haviam sido expatriados anteriormente para países diversos.

Dentre os 12 entrevistados, cinco foram sozinhos (E1, E4, E6, E8 e E9), dois foram acompanhados pelo cônjuge (E2 e E7), três estavam na China com o cônjuge e filho(s) (E3, E5 e E11) e os outros dois (E10 e E12) oscilaram períodos em que a família estava junto na China e outros voltava para o Brasil. No momento da entrevista, E4, E9 e E11 já eram repatriados, isto é, sua missão no exterior já havia terminado e já estavam de volta no Brasil.

Em relação ao roteiro de entrevista, foi elaborado um instrumento abordando: a história de vida no Brasil, a experiência de trabalho no Brasil, a vida na China, a experiência na empresa da China e o processo de resiliência. As perguntas foram elaboradas com o objetivo de instigar o entrevistado a relatar sobre situações vivenciadas durante sua experiência de expatriação que provocaram estresse, que se caracteriza como uma premissa para o surgimento do comportamento resiliente, foco deste artigo. As entrevistas, que tiveram duração aproximada de uma hora, foram realizadas e gravadas por Skype (comunicação de áudio e vídeo pela internet) e posteriormente transcritas.

Para a análise dos dados, utilizou-se a técnica de análise de conteúdo, especificamente a análise categorial, sendo as categorias de análise definidas a priori, a partir da teoria referida sobre o tema. De acordo com Bardin (2011), a análise de conteúdo é um conjunto de técnicas de análise de comunicações que visa obter indicadores que permitam a inferência de conhecimentos relativos às variáveis inferidas dessas mensagens.

As categorias de análise definidas para este estudo são relacionadas ao comportamento resiliente, com base em Grotberg (2005) e Minello (2014), e se constituem em: situações de adversidade e dinâmica do comportamento resiliente, conforme a Figura 4. 
Figura 4: Quadro de referência para definição das categorias de análise a priori

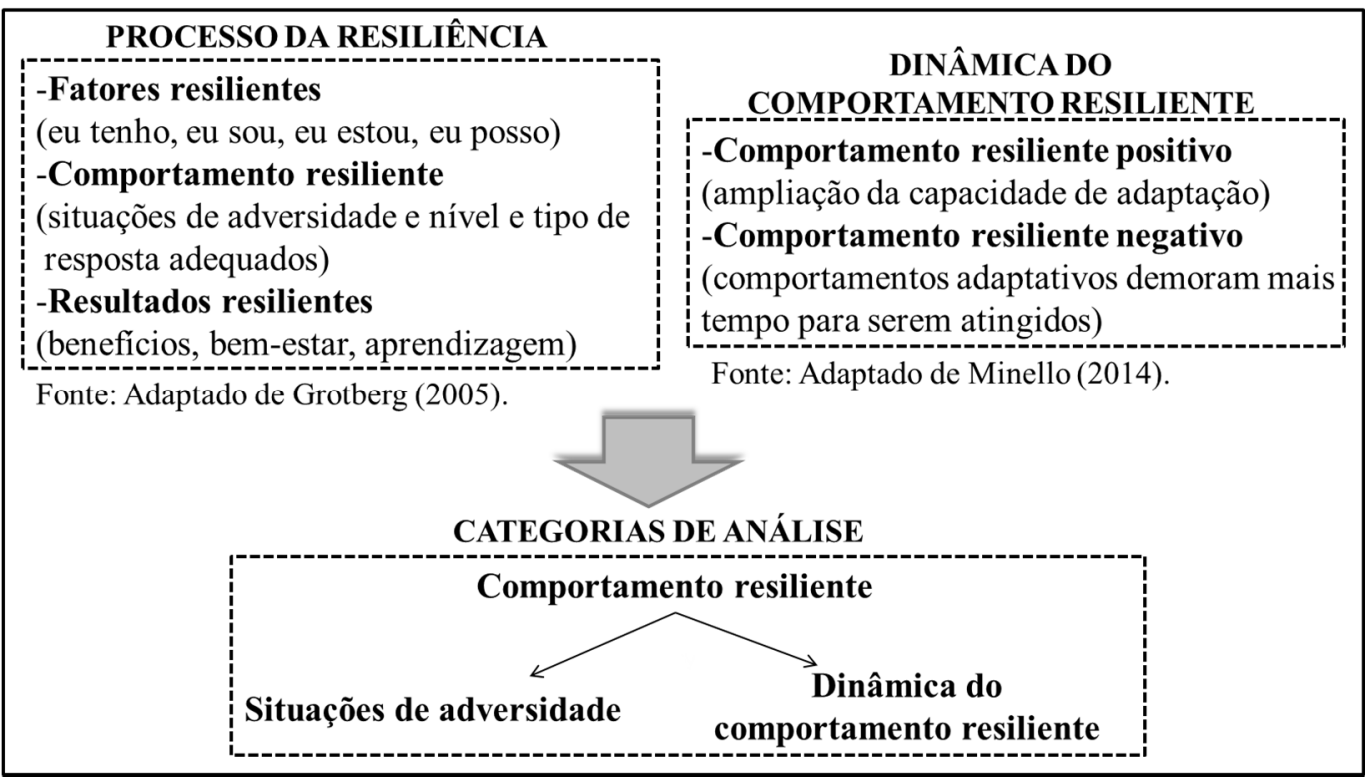

Fonte: Desenvolvida pelos autores com base em Grotberg (2005) e Minello (2014).

A seguir, apresenta-se a análise das categorias definidas a priori.

\section{ANÁLISE DOS RESULTADOS}

Nesta seção, primeiramente é apresentada a categoria "Situações de adversidade" e em seguida a categoria "Dinâmica do comportamento resiliente". Ao final deste tópico, é realizada uma amarração das categorias que entrelaçam as teorias do processo dinâmico da resiliência e da curva de aculturação.

\subsection{Situações de adversidade}

Tendo como base a ideia de Grotberg (2005), que argumenta que a mudança de país pode ocasionar situações adversas na vida de uma pessoa, esta categoria de análise evidencia as situações de adversidade relacionadas à experiência de expatriação de brasileiros na China. Masten (2011), DiCorcia e Tronick (2011) e Masten e Cicchetti (2016) sinalizam que a superação de situações adversas extremas ou extraordinárias geralmente são associadas à resiliência, contudo, estes pesquisadores consideram que a resiliência também está relacionada a situações de estresse do dia a dia. Estas situações, por sua vez, se formam a partir de mudanças de certas condições de vida as quais não eram esperadas (ARMSTRONG et al., 2011).

Ao chegar à China, os expatriados já sentiram o impacto de estar em um país diferente do seu. Segundo Hofstede (1991), isso está relacionado ao contato intercultural, que é geralmente acompanhado de processos psicológicos e sociais típicos, em que o indivíduo estrangeiro normalmente sofre 0 impacto do choque cultural. Para Collie et al. (2010), em um primeiro momento, o estrangeiro não consegue se identificar com aquela cultura diferente da sua, visto que não faz parte do seu modelo mental, o que pode lhe gerar incômodo. Esta ideia pode ser constatada nos relatos de E1 e E4, no momento em que chegam à China.

E1 - Só que eu cheguei aqui a primeira semana e eu queria voltar, ir embora de tudo que é jeito e eu andava nas ruas eu tinha ânsia de vômito, vontade de vomitar, era um cheiro insuportável, era um cheiro insuportável... as pessoas cospem em ti, e é um fedor, um fedor,... Saí de havaiana na rua tomei um cuspe no pé, que eu nunca mais saí de havaiana na rua. Porque eles têm mania de cuspir em tudo, porque eles cospem assim ó "tch tch" o tempo inteiro. Cospem, cospem. Guria do céu! Parece que está chovendo às vezes. E quando chove não tem como tu andar de havaiana. Porque fica aquela água grudando no pé. Acho que acumula cuspe com tudo. 
E4 - Lá é muito estressante então a gente sai de lá muito estressada, querendo relaxar um pouco [...] até pegar táxi estressa lá porque...você dá sinal, aí chega um velhinho, e como eles não respeitam fila, eles saem correndo e pegam teu táxi na tua frente, você tá lá na fila do mercado esperando, esperando vem um chinês e corta tua fila, tipo as pequenas coisas os costumes deles que dá vontade de pegar e "matar" né, o chinês.

As dificuldades em relação à adaptação cultural, familiar, com o idioma estrangeiro, conforme Gallon e Scheffer (2015), tomam uma proporção inesperada ao expatriado, se sobressaindo em relação às preocupações com seu desenvolvimento e crescimento no trabalho. Esta dificuldade em interagir com a cultura de outro país culmina em conflito para o indivíduo (MACHADO; HERNANDES, 2004). Diante disso, podem emergir sentimentos de angústia, impotência e hostilidade face ao novo ambiente (HOFSTEDE, 1991). Uma das dificuldades que causam esse tipo de sentimento, vivenciada pelos brasileiros entrevistados neste estudo, está relacionada ao obstáculo do idioma da China, conforme relata E3.

E1 - A gente vai tentando vai aprendendo inglês, aí pede informação na rua. Tem uns que sabem falar inglês na rua, tem uns que não sabem. Às vezes a gente passa perrengue. Às vezes a gente fala a língua. A gente fala o endereço e falo errado, vai parar em outro lugar. Fica desesperada. Entendeu?! Acontece muita coisa assim que... que dá pânico. Aí tu fica, tu começa a ficar desesperada.

E3 - Outra coisa que é estressante e que a gente não percebe quando está lá, mas percebe quando volta no Brasil, vou te dar um exemplo assim: a primeira vez que voltei para o Brasil, que cheguei no aeroporto, eu olhei para as paredes e eu vi propaganda em português de banco de qualquer outra porcaria que seja. Eu olhei e conseguia ler, e pessoas passaram por mim e eu entendia o que estavam dizendo, então, [...] só aí eu me dei conta o quão isolados nós estamos lá, porque a gente não lê nada, ou seja, tudo ideograma, a gente não entende 0 que as pessoas falam. Então a gente acaba ficando num mundo totalmente à parte e isso gera um estresse que a gente não percebe, mas que está lá, dentro da pele da gente.

De acordo com a Câmara Brasil-China (2017), o mandarim é a língua oficial da China, que serve como base para centenas de dialetos falados em diferentes regiões de todo o país. Já para a realização de negócios internacionais, Pimentel (2009) comenta que o idioma mais utilizado é o inglês, porém os principais executivos chineses não dominavam o inglês, o que dificultava a efetivação da comunicação nos negócios. Outro aspecto influenciador neste contexto, na visão do autor, é o fato de que o expatriado se depara com uma mistura de idiomas e dialetos que passa a fazer parte do seu dia a dia. Tal situação pode ser uma das causas geradoras de estresse, pois mesmo tendo domínio da língua inglesa, os expatriados entrevistados tiveram certa dificuldade, principalmente nos locais fora da empresa em que o mandarim era necessário, como pode ser observado nos trechos do relato de E2.

\footnotetext{
E2 - As coisas aqui são bastante ineficientes, se você tem que ir ao banco, você passa o dia inteiro no banco, até você encontrar alguém que fale inglês, alguém com quem você está querendo falar. Essas coisas são estressantes, sabe. Você querer ir ao banco a primeira vez que você muda para cá, você não consegue falar chinês, não sabe explicar o que você quer, ninguém que fale inglês. Uma coisa que normalmente demoraria quinze, vinte minutos, para você abrir uma conta, demora cinco horas.
}

Hofstede (1991) afirma que as diferenças de idioma contribuem para erros de percepção em matéria cultural. Por outro lado, embora seja difícil a compreensão do mandarim e do inglês falado por um chinês, o que ocorre em muitas situações é que o conhecimento do idioma acaba sendo secundário, pois o que ajuda a compreender o contexto é a capacidade de compreensão cultural (PIMENTEL, 2009). Essa ideia é percebida nas falas de E3 e E5. 
E3 - Uma das dificuldades que eu tive foi de, justamente no início, não entender direito a maneira de pensar e o que fazer para fazer as coisas acontecerem, ter um resultado melhor, então isso de certa forma é estressante.

E5 - A questão da comunicação, e eu não estou falando aqui do idioma, eu estou falando da forma que as pessoas pensam aqui. A maneira como o raciocínio é processado é diferente da maneira que você processa o raciocínio no Brasil, né, então não é só você falar mandarim que vai resolver a vida, é uma questão muito mais cultural, tá? É uma questão muito mais do processamento do seu raciocínio que é diferente do processamento do raciocínio do ocidental, né.

Segundo Fonseca (2011), a comunicação verbal, dentro da comunicação intercultural nas organizações, assume especial importância na medida em que é a principal forma de se esclarecerem dúvidas e justificar os desvios entre funcionários da matriz e da subsidiária. No entanto, Nunes et al. (2008) descrevem que ocorrem situações de rejeição ao indivíduo expatriado que influenciam na manutenção desse clima, como pode ser percebida em E7 e E8.

E7 - Eles esperam que você saiba tudo, então as pessoas também não falavam comigo no começo, falavam o mínimo necessário não tinha nenhum tipo de interação que não fosse de trabalho, então se eu não precisasse falar com ninguém sobre trabalho naquele dia, eu entrava muda e saía calada do escritório. Não rolava nenhum bom dia, nada, absolutamente nada, a não ser com a minha chefe, quando ela estava lá, eu tinha uma interação - oi, bom dia, tudo bem, por mais que eu não precisasse falar diretamente com ela, mas com todos os outros colegas do trabalho não.

E8 - Tive uma dificuldade muito grande com meu chefe direto que era chinês e assim, discussões homéricas, várias brigas com ele, por conceitos, coisas que ele achava que eram corretas, e que eu por valor pessoal achava incorreto, não topava fazer, então tive muitas brigas com esse chefe chinês!

Nunes et al. (2008) afirmam que os expatriados servem como elementos de ligação, já que podem adquirir conhecimento essencial para a tomada de decisão da empresa. Wang et al. (2009) e Cantoni e Giustiniano (2015) parecem complementar essa abordagem ao afirmarem que uma das principais atividades do expatriado é transferir o conhecimento da matriz para a subsidiária e vice-versa.

No caso de E12, o papel de ligação entre a matriz e a subsidiária representa uma sobrecarga no trabalho do expatriado, pois exige a sua presença em demasia, o que acaba sendo uma tarefa estressante. Isso acontece devido à diferença no fuso horário entre o Brasil e a China, implicando na necessidade de o expatriado estar presente na empresa no horário comercial dos dois países, o que aumenta consideravelmente a sua carga-horária de trabalho. Tal situação vivenciada por E12 é semelhante aos resultados da pesquisa de Pimentel (2009), em que o fuso horário foi citado como um elemento que oferece barreiras para as empresas brasileiras na China, já que a diferença de 11 a 12 horas no fuso horário dificulta reuniões com a matriz. Pode-se perceber que essa situação representa uma das adversidades do cotidiano do expatriado, o que também influencia em sua vida pessoal, como se pode identificar nos relatos de E5 e E12.

E5- Outra grande dificuldade pra nós é o fuso horário, isso é um caso bastante sério, porque a gente tem que falar muito com o Brasil ainda. Se você trabalha com o headquarter no Brasil, você acaba trabalhando muito mais do que o normal, porque você pega o horário da China pra trabalhar coisas de China e quando você se dá conta, o Brasil está começando a abrir e como você depende muito do Brasil ainda para uma série de coisas, a maioria das empresas aqui ainda depende do Brasil para tomada de decisão, algumas estruturas e algumas facilidades ainda ficam no Brasil, então isso tudo acarreta você trabalhar no horário do Brasil e no horário da China.

E12 - Esse é um ponto negativo eu acho de trabalhar na China, porque a rotina é muito pesada, além, eu trabalho durante o dia no escritório, praticamente todos os dias no escritório, só que o contato com a base no Brasil é a noite, isto dá pra dizer que a gente tem uma jornada de 
trabalho aí que começa às sete horas da manhã e praticamente vai até a meia noite, quase todos os dias. No meu caso como eu tenho contato com um grupo de empresas inteira, então tenho pessoas de contato em todas as empresas praticamente todos os dias diferentes, eu tenho que falar com alguém.

Em um contexto intercultural, algumas pessoas são mais propensas do que outras a ter a capacidade de gerir o estresse e a ansiedade, muitas vezes associada a como fazer novos amigos, a fim de ter um apoio social (CALIGIURI; TARIQUE, 2012). Freitas (2010) ressalta a questão de se sentir sozinho em um país estrangeiro; nesse sentido, a autora comenta sobre a adaptação da família, pois enquanto o pai, funcionário expatriado, está na empresa, a mãe e os filhos ficam sozinhos em casa, o que os faz sentir-se fragilizados, ao mesmo tempo em que a mãe tem que ser forte para dar suporte aos filhos. A exposição a eventos adversos da vida, como esse, normalmente prevê subsequentes efeitos negativos sobre a saúde mental e o bem-estar dos envolvidos (SEERY et al., 2010), assim como relatam E3 e E11 a seguir.

\begin{abstract}
E3 - A gente estava sozinho, éramos nós três, eu, a minha esposa e meu filho e aí tu conhece alguém, por exemplo, é uma certa dificuldade, primeiro para encontrar alguém, né, não existia toda essa rede, Facebook na época era bem limitado ainda, então até conhecer alguém para ter uma relação mais de amizade e até casar com a pessoa, porque se tu encontrar alguém não significa que tu tenha afinidade e aí, normalmente as pessoas ficam seis meses, um ano e vão embora. Então cada vez que a gente constrói uma relação e conhece as pessoas, aquela pessoa vai embora e fica uma sensação de perda, porque a gente está sozinho de novo e aí tem que começar tudo do zero, com outras pessoas e tal, então é um pouco frustrante no início.

E11 - Como eu estava trabalhando o dia todo eu não sentia muito. A família, ela sentia mais. A questão da convivência já que não tinha tanto brasileiro tinha até um grupo bom, mas não tinha tanto, então não tinha muito com quem conversar, conviver porque muito difícil, a gente tá no interior então até mesmo os chineses que falavam inglês eram poucos, também tinham uma dificuldade grande pra poder se comunicar com o pessoal, aí isso deixava a gente um pouco abatido no início.
\end{abstract}

Para DiCorcia e Tronick (2011), as pessoas vivem em um mundo de relações sociais complexas e mutáveis e de situações voláteis, o que faz modificar o seu comportamento para lidar com essas situações diárias. Esta perspectiva vai ao encontro dos relatos dos expatriados brasileiros entrevistados, que apontam que as situações de adversidade vivenciadas na China estão atreladas às situações de seu cotidiano. Para Dicorcia e Tronick (2011), o estresse do cotidiano ajuda quando o indivíduo tem que passar por uma adversidade mais intensa. Essas mudanças se tornam desafios para as pessoas, as quais, à medida que vão se adaptando, ampliam a sua capacidade de lidar com as situações que estão Ihes perturbando (ARMSTRONG et al., 2011).

\title{
5.2 Dinâmica do comportamento resiliente
}

Bergamini (2005) afirma que os problemas e as situações desagradáveis ou adversas exigem de cada indivíduo a busca de recursos ou de condições para alcançar soluções mais confortáveis para minimizar as repercussões do processo de ruptura provocado. Segundo a autora, cada ação do indivíduo diante da adversidade demanda esforço e recursos pessoais a serem utilizados, no entanto isso não significa que tais recursos se esgotem definitivamente; pelo contrário, eles vão recompondo-se e, a cada adversidade superada, o indivíduo sente-se fortalecido e mais predisposto a enfrentar novas etapas da vida. Esta caracterização está relacionada com o conceito de resiliência como um processo dinâmico de Rutter (2012) e Luthar et al. (2014) e com a ideia de Grotberg (2005), que evidencia a dinamicidade da resiliência ao relatar que, diante de uma adversidade, em um primeiro momento um indivíduo reage de um jeito e, em outro momento, manifesta um comportamento diferente, pensando em uma melhor alternativa.

Analisando o comportamento dos entrevistados, por meio de seus relatos, pode-se dizer que as situações vivenciadas por eles passaram por um processo dinâmico as quais resultaram ora em um comportamento resiliente positivo, ora em negativo. As falas de E4 e E5 exemplificam essas colocações. 
E4 - No começo, a primeira vez que fui eu não peguei o ritmo, não me adaptei. Tipo, que eu te falei, tipo deles serem bem diferentes da gente e eu realmente no começo não me adaptei a eles, a essa mudança só com o tempo mesmo.

E5 - Eu me sinto bem, eu acho que estou adaptado sim. Tem esses altos e baixos, de vontade de ir embora, como te disse, às vezes, dá isso, né, por estresse, não aguento mais, chega, já deu, vou-me embora! Isso acontece, mas não é uma questão relacionada à adaptação, no meu caso não é relacionado à adaptação. A minha adaptação foi muito boa, porque eu considero Shangai uma cidade fácil de se adaptar, se você não se adaptar em Shangai é porque você está com algum problema.

Assim como um indivíduo pode mudar o seu comportamento e reagir de uma forma diferente perante a mesma situação (GROTBERG, 2005); uma mesma situação pode causar reações distintas em pessoas diferentes. Seery et al. (2010) explicam esta colocação no sentido de que quando uma situação adversa acontece, para algumas pessoas, o sentimento de mal-estar, de não estar satisfeito com a sua vida, pode durar bastante tempo, até mesmo anos; já para outras, frente a uma mesma situação, são capazes de se recuperar rapidamente. Podese evidenciar no relato dos entrevistados uma perspectiva semelhante em relação à vontade de permanecer na China. No caso de E1 e E6, a China lhes parece um lugar bom de morar, o que caracteriza um comportamento resiliente positivo.

\begin{abstract}
E1 - Eu adoro cara, eu adoro. Adoro tipo assim. Saber que eu estou aqui, que eu estou me virando, vê que eles têm muita gente boa também sabe. A minha vida eu quero fazer aqui. Eu não tenho vontade de tipo, de voltar pro Brasil, morar. Mas os meus planos mesmo é ficar aqui tipo porque eu já conheço um monte de gente aqui, já me dou bem com eles, já sei a cultura deles, já me adaptei totalmente. Não tenho nada contra. Gosto. Sabe?! Me sinto em casa mesmo. E ham... Assim quero, quero, quero trabalhar tipo assim com exportação e tal... A gente vai fazer um curso até agora.

E6 - Às vezes, as pessoas do Brasil, quando elas conversam com você, às vezes até falam, ah mas você é fria, você acaba se tornando uma pessoa fria, mas não é questão de se tornar fria, é que você tem que fazer isso para sobreviver, porque senão, se você ficar comparando, ficar relembrando, se você ficar remoendo, você nunca vai ser feliz aqui. Hoje em dia minha casa é aqui, o meu lar é aqui, o que eu tenho é isso daqui, então eu tenho que me adequar com tudo que está aqui.
\end{abstract}

Já para E5 e E8, estar na China provoca sentimentos de insatisfação, de querer voltar para o Brasil. As falas desses entrevistados encontram respaldo em Minello (2014), que relata que a pressão provocada pela adversidade abala o estado emocional do indivíduo, o que caracteriza um comportamento resiliente negativo neste momento.

\footnotetext{
E5 - Eu, hoje, por exemplo, estou num momento desses, se pudesse vir me embora eu vinha, mas eu sei que é uma fase, não é, eu tenho uma missão, um contrato para cumprir aqui e eu sei que é um momento psicológico dessa curva dos expatriados que eu estou passando, daqui um pouquinho vai equilibrar um pouco mais, vai passar essa fase que eu estou, que é estar de saco cheio, entendeu?!

E8 - Olha, eu já tava com sentimento de eu quero voltar pra casa, e pra mim tinha muito claro que assim, a China é um lugar super legal pra fazer negócio, mas eu jamais criaria um filho meu aqui nesse país, é, então quando você começa a pensar dessa forma você não consegue ver um futuro pra você a longo prazo, eu estava mais inclinado a querer voltar logo, o quanto antes, não aguento mais isso aqui!
}

Ao observar o desejo dos entrevistados de voltar para casa, evidencia-se a ideia de Bergamini (2005) que diz que, em situações difíceis, um reduto de forças internas é solicitado para gerar possíveis soluções para um impasse, o que promove o desgaste interno ou psicológico do indivíduo. A compreensão desse desgaste demanda 
energia do indivíduo no sentido de superá-lo, visto que quando ele se vê diante de um impasse ou de uma situação de adversidade, reage para livrar-se da situação conflitiva (BERGAMINI, 2005). No entanto, segundo Minello (2014), o esforço para alcançar soluções pode provocar desgaste psicológico e culminar na redução da energia psíquica do indivíduo, proporcionando uma pressão interna que consome a energia ou o "tônus vital", gerando apatia, perda de motivação, estresse e depressão. No caso de E4 e E5 a compreensão desse desgaste está relacionada às diferenças culturais enfrentadas ao trabalhar diretamente com os chineses, o que, neste momento, evidencia um comportamento resiliente negativo.

\begin{abstract}
E4 - Então da minha primeira vez na China eu não suportei chinês, tipo tinha muita raiva. A minha primeira impressão foi péssima deles eu já olhava pra eles achando que ia brigar com eles com cara feia e tudo. Acho que primeira vez que eu fui, por exemplo, o fuso, as diferenças tipo, quando eu mudei tipo o nosso organismo também acaba mudando, então acabei ficando mais magra, tipo até me acostumar com a comida chinesa e até se acostumar assim com costumes deles.

E5 - A vida do expatriado ele passa por altos e baixos, geralmente você chega está tão envolvido no trabalho e nas novidades que tudo é legal, tem uma curva, não é?! Eu, por exemplo, agora, eu estou no auge do saco cheio, se pudesse largar tudo e voltar para o Brasil para fazer sei lá o que, eu faria. Chega uma hora que enche, entendeu? Você se cansa de dar murro em ponta de faca, você se cansa de trabalhar em dois fusos, você se cansa de explicar, explicar, explicar para ver se eles entenderam realmente o que você tá querendo e depois você tem que ir lá e checar.
\end{abstract}

De acordo com Collie et al. (2010), o expatriado deve buscar interagir com o nativo, se misturar e, ao mesmo tempo, ter a consciência que precisa se desapegar dos modelos mentais ou referências de suas origens, senão vai se sentir estressado constantemente. No entanto, para Nunes et al. (2008), a cultura anfitriã pode não favorecer um espaço de abertura e receptividade aos expatriados. Esta descrição se assemelha com o que ocorreu com E6 e E8, em que houve um esforço por parte desses entrevistados para conseguirem compreender e interagir com os chineses, porém essa interação e compreensão foram dificultosas.

\footnotetext{
E6 - Eu sei que eu vou chegar em casa e vai ser só eu, eu não vou ter a quem recorrer ou então mesmo que eu vá conversar com alguém, com algum chinês, ele não vai entender qual que é minha situação, então assim, por isso que às vezes a gente acaba se entrosando muito mais com brasileiros.

E8 - Tinha uma diferença muito clara entre meu relacionamento com os chineses e os outros colegas. Com os outros colegas fluía muito mais, porque eles também eram estrangeiros e pra mim a China é tão diferente dos outros países, que qualquer um que está lá se sente excluído e forma um pequeno grupo de pessoas que não é chinês.
}

Conforme descreve Freitas (2010), a diversidade multicultural propõe ao indivíduo o desafio de se construir condições favoráveis à sua expressão de forma equilibrada, colaborativa e complementar, sem prejuízo das necessidades psicológicas e emocionais que fazem parte de todo ser humano. Esse é um momento em que o indivíduo passa a construir uma nova identidade social, a partir da interação com os outros e dos processos de integração com a cultura (MACHADO; HERNANDES, 2004); quanto maior a aproximação com uma identidade global, maior o nível de satisfação com suas vidas. Nesse sentido, Morgan (1996) acredita que o estrangeiro pode aprender até o ponto de sentir-se como um nativo, como é o caso de E7. No entanto, para Hofstede (1991), é pouco provável que ele possa identificar e ainda mais sentir os valores dessa outra cultura, como é o caso de E2.

E7 - Acho que para entrar dentro da cultura você precisa vivenciar a cultura como um todo, então é importante aprender o idioma, porque, primeiro que o idioma faz parte da cultura de um povo e segundo que você só consegue coisas quando você sabe o idioma. E no meu trabalho eu tinha que saber falar pelo menos, coisas do dia a dia do trabalho, sei lá, essas pequenas coisas tem que saber falar e aí também, pelo meu próprio interesse pessoal em aprender, mas cansa, né. 
E2 - Eu gosto muito de diferentes culturas, de conhecer diferentes países, eu sou aberta para morar em qualquer lugar, para te falar a verdade, que não seja frio. Eu gosto de morar aqui, me sinto bem, me sinto adaptada, mas não me sinto chinesa não, nem quero me sentir. Sou brasileira com muito orgulho.

De acordo com Coutu (2002), uma das características do comportamento resiliente é a firme aceitação da realidade, uma crença profunda, geralmente apoiada em valores fortemente sustentados, de que a vida é importante e significativa. Isso sugere que o comportamento resiliente está relacionado à habilidade de perceber a realidade a partir do estabelecimento de significados para a situação adversa. Para Caligiuri (2000), este comportamento se traduz na estabilidade emocional, uma característica da personalidade de expatriados para se ajustarem no estrangeiro. Seery et al. (2010) complementam esta ideia ao descrever que a estabilidade emocional permite ao indivíduo criar uma capacidade de resistência e uma probabilidade de avaliar as situações futuras de maneira mais otimista, é a capacidade de perceber que é possível lidar com isso. Essa perspectiva pode ser observada nos relatos de E3 e E9.

\begin{abstract}
E3 - No trabalho também bem difícil, os chineses não são abertos de maneira nenhuma, eles não te dizem o que eles estão pensando, eles não afrontam, eles não dizem que sim, nem que não, então foi uma adaptação para entender como culturalmente eles se comportam, como que eu deveria administrar ou gerir a parte que eu era responsável para conseguir resultado. Então que nem gato, vai tentando e voltando até conseguir estar firme, e isso leva seguramente entre quatro e seis meses, oito meses até tu ter realmente segurança no que tu está fazendo.

E9 - Muitas vezes eu tinha que dar uma parada, respirar fundo e bom vou entrar no ritmo deles, né, então tive que me adaptar em algumas coisas, e com certeza, outras aonde eu pude imprimir o meu ritmo, eles tiveram que se adaptar ao meu ritmo, né, mas sempre quando se está num país que não é o teu, o sucesso vai depender da adaptabilidade que tu vai ter à cultura local, né, já que tu é que é o diferente, tem que se adaptar ao deles claro.
\end{abstract}

Além da estabilidade emocional, outra característica que reflete no comportamento resiliente é a competência dinâmica de tolerância à ambiguidade. Para Caligiuri e Tarique (2012), tolerância para a ambiguidade é a capacidade de gerenciar situações novas, ambíguas, diferentes e imprevisíveis. Os autores argumentaram que as pessoas com maior tolerância para a ambiguidade são mais propensas a gerir eficazmente 0 estresse imposto pelo ambiente de incerteza e de ser mais adaptável e receptivo a mudar e as condições de rápida mudança. Nessa mesma perspectiva, Seery et al. (2010) sinalizam que lidar com o estresse permite uma sensação de controle e domínio da situação, o que permite sensação de segurança para lidar com novas situações. Este contexto pode ser percebido nas falas de E3 e E7.

\footnotetext{
E3 - Eu não me estresso muito fácil eu tenho uma boa resiliência em relação ao meu trabalho, não tive maiores problemas em relação a isso, claro preocupações de trabalho, fazerem as coisas acontecerem, tem que estar sempre fiscalizando, indo na fábrica, sábado, domingo, de noite, para mostrar presença para fiscalizar, mas não me estresso assim, alguma coisa que realmente me afetasse.

E7 - Eu sou super metódica, eu odeio quando as coisas saem fora do eixo, saem fora do prumo eu realmente fico irritada, fico muito nervosa, quando alguma coisa sai fora do meu esqueminha e eu tive que aprender a lidar com isso na marra, porque tudo sai fora do esquema hahaha, já estar dentro do esquema é concluir que alguma coisa vai sair fora dele, entende. Eu tenho já que trabalhar com o elemento surpresa.
}

A partir dos relatos dos entrevistados, pode-se observar que os expatriados vivenciaram diferentes situações em sua experiência na China, que provocaram uma dinâmica em seu comportamento resiliente, ora positivo, ora negativo, perante as situações de estresse do cotidiano. Conforme explanado por Seery et al. (2010), ao enfrentar a adversidade, o indivíduo aprende habilidades eficazes de enfrentamento, para se envolver em redes 
de apoio social, criar um senso de domínio sobre a adversidade passada, promover crenças na capacidade de lidar com sucesso no futuro e gerar resistência psicológica e física.

\subsection{Amarração das categorias: a relação entre o processo dinâmico de resiliência e a curva de aculturação}

Ao analisar as categorias "Situações de adversidade" e "Dinâmica do comportamento resiliente", cabe resgatar a curva de aculturação de Hofstede (1991) - (Figura 2), pois se pode perceber que o processo de resiliência apresenta pontos que se assemelham intimamente às fases de adaptação do expatriado.

As situações de adversidade relatadas pelos entrevistados são exemplificadas pelo desequilíbrio físico e psicológico devido a hábitos de higiene e alimentação, cheiros, gestos, e sentimentos de hostilidade pela longa jornada de trabalho, fuso horário, idioma, dificuldade de se relacionar com os chineses. Estas consistem em desilusões e frustrações em relação ao país estrangeiro, tal qual é descrita a fase de choque cultural de Hofstede (1991) e demais autores que também apresentam esta etapa em sua curva de adaptação, como Black e Mendenhall (1991) e Cerdin (2002) apud Nunes et al. (2008).

A dinâmica do comportamento resiliente, por sua vez, está atrelada à fase de aculturação, que significa que gradualmente o expatriado brasileiro na China foi se ajustando aos valores locais e à nova cultura. Isto não significa que, mesmo depois de um tempo no país destino, uma vez se sentindo ajustado, os estresses cotidianos pararam de se manifestar. Ao contrário, eles continuam e são intercalados em momentos que é possível conviver bem e outros que ainda causam estranheza. Esse resultado também pode ser associado com a quarta fase da curva, denominada situação estável, que apresenta os três pontos "a, b, c", que ilustram as variações na estabilidade do estrangeiro (HOFSTEDE, 1991). Ao fazer uma releitura deste enfoque com a dinâmica do comportamento resiliente sobre a resiliência, a letra "b" traduz a resiliência original; a letra "c", o comportamento resiliente positivo; e a letra "a", o comportamento resiliente negativo.

A letra "a", que fica no eixo negativo do gráfico de Hofstede (1991), representa os sentimentos negativos em relação ao país estrangeiro, onde 0 expatriado ainda se sente um estranho. Esta situação foi observada nos entrevistados pelos relatos de sentimento de negação, momentos de angústia e isolamento, o que permite dizer que nestes exemplos os expatriados levaram um tempo maior para atingir a adaptação ou para se recuperar totalmente do estresse, o que ilustra o seu comportamento resiliente negativo.

Já a letra "b", que fica entre o eixo positivo e negativo, representa o sentimento de sentir-se igualmente, tão bem quanto antes e, nesse caso, pode-se considerar que o visitante conseguiu uma adaptação bicultural. Esta situação estaria de acordo com a resiliência original, que ocorreria de forma natural e plena, sugerindo que 0 expatriado sentiria um conforto psicológico semelhante ao que sentia em sua terra natal (MORGAN, 1996), que seria acreditar que o estrangeiro poderia aprender até o ponto de sentir-se como um nativo. No entanto, os relatos evidenciaram que a vida social dos expatriados foi construída separada dos chineses, formando-se grupos de brasileiros ou de estrangeiros e não uma adaptação a ponto de sentir-se como um nativo. Visto isso, este conceito não foi evidenciado nas categorias de análise, dando ênfase apenas a dinâmica do comportamento resiliente positivo e negativo.

Por último, a letra "c" representa que o estrangeiro se sente melhor ainda, que se adaptou totalmente ao modo de vida de seus anfitriões, porém não se sente um nativo. Esta situação foi evidenciada pelo sentimento de aceitação das adversidades. A consciência das diferenças culturais ajudou os expatriados a levar uma rotina de vida de expatriado na China e a enfrentar as situações de adversidades do dia a dia, respeitando as peculiaridades de cada indivíduo e da cultura do país. Isto significa que o indivíduo apresentou uma capacidade ampliada de adaptação e recuperação, pois buscou experiências passadas ou técnicas que 0 ajudaram a superar as adversidades, o que consiste em um comportamento resiliente positivo.

Nessa perspectiva, ao visualizar as variações a, b e c da curva de aculturação de Hofstede (1991), inferese que essa concepção está atrelada à teoria referente ao processo de resiliência (GROTBERG, 2005; MINELLO, 2014). No caso dos expatriados, as situações de estresse foram os choques culturais vivenciados, que provocaram comportamentos resilientes distintos, positivos e negativos. Nesse momento, o expatriado pode utilizar estratégias de enfrentamento para lidar com essas situações adversas. Assim, emerge a dinâmica do comportamento resiliente sobre o processo da resiliência sob o ponto de vista do expatriado. 


\section{CONSIDERAÇÕES FINAIS}

Resgatando o objetivo deste artigo - analisar o comportamento resiliente de brasileiros expatriados na China diante da experiência de expatriação -, pode-se dizer que o objetivo foi alcançado, pois foi possível perceber a dinamicidade do comportamento resiliente dos entrevistados, ora positivo, ora negativo, diante das situações estressoras ou de adversidades provocadas pela experiência de expatriação.

Como resultados, pode-se ressaltar que a maioria dos fatores estressores salientados pelos expatriados estava relacionada a aspectos pertencentes à cultura do país de expatriação, a China. Ficou evidente o impacto do choque cultural sobre o comportamento dos entrevistados ao mencionar os fatores que the causaram estranheza, como os diferentes hábitos de higiene e alimentação, cheiros, gestos, provocando muitas vezes reações de revolta, pois estes eventos não são típicos de sua cultura de origem. Na atividade profissional, o fuso horário foi um elemento que contribuiu para o estresse dos expatriados devido à longa jornada de trabalho para participar das atividades da empresa tanto no horário do Brasil quanto da China. Destaca-se a proeminência das adversidades causadas pela comunicação em mandarim, já que a maioria dos expatriados não tinha domínio para ler e falar no idioma. Isto dificultava a relação com os chineses e a realização de atividades simples do cotidiano, como se locomover na cidade e ser atendido em estabelecimentos comerciais, por exemplo. Além do idioma, outro problema relacionado à comunicação se devia à dificuldade de interpretar a maneira de pensar dos chineses, que se diferencia dos padrões brasileiros, o que acabava dificultando as relações de trabalho com os nativos.

Diante dessas situações, em um primeiro momento a reação espontânea dos expatriados era a negação e, com o tempo, a aceitação, culminando no sentimento de adaptação durante esta experiência. Claro que esta ordem de acontecimentos pode ser alterada, tendo em vista a existência da oscilação entre momentos de estabilidade emocional e momentos de angústia e isolamento. Salienta-se que, como resultado de seu comportamento resiliente, a vida social dos expatriados foi construída separada dos chineses, formando-se grupos de brasileiros ou de estrangeiros. A consciência das diferenças culturais ajudou os expatriados a levar uma rotina de vida de expatriado na China e a enfrentar as situações de adversidades cotidianas, respeitando as peculiaridades individuais e culturais.

Como principal contribuição deste estudo, destaca-se o dinamismo do comportamento resiliente dos expatriados entrevistados, ora positivo, ora negativo, diante das situações estressoras ou de adversidades provocadas pela experiência de expatriação. Este fato vai ao encontro com a curva de aculturação do expatriado, que demonstra o movimento dos sentimentos e do comportamento do indivíduo no estrangeiro (HOFSTEDE, 1991). Isto significa que, ao longo da experiência, o expatriado vai passar por diversas situações diariamente que podem Ihe causar estresse e a maneira de lidar com elas pode oscilar entre comportamentos resilientes positivos e comportamentos resilientes negativos. Por fim, considerando o amplo escopo de atributos e competências necessárias aos profissionais que vão para o exterior, destaca-se a resiliência como uma característica necessária aos profissionais expatriados, tendo o comportamento resiliente contribuído para resultados positivos, como uma aceleração da aprendizagem e do amadurecimento do indivíduo tanto pessoal quanto profissionalmente. Diante disso, percebe-se a importância do processo da resiliência para o sucesso da experiência de expatriação.

Como limitação, apresenta-se o fato deste estudo ter como foco somente um aspecto do processo dinâmico da resiliência, o comportamento resiliente. Para estudos futuros, sugere-se ampliar o escopo de análise sobre os fatores resilientes e os resultados resilientes que fazem parte desse sistema dinâmico. Sugere-se também ampliar os estudos empíricos sobre o processo de resiliência na Administração para outros sujeitos em contexto de trabalho, pois ao considerar a resiliência como uma característica necessária ao sucesso da expatriação, entendese que esta característica é estendida a todos os profissionais que trabalham sob pressão e incertezas que podem provocar estresse.

\section{REFERÊNCIAS}

ARMSTRONG, A. R.; GALLIGAN, R. F.; CRITCHLEY, C. R. Emotional intelligence and psychological resilience to negative life events. Personality and Individual Differences . v.51, p.331-336, 2011.

BARDIN, L. Análise de Conteúdo. São Paulo: Edições 70, 2011.

BARLACH, L.; LIMONGI-FRANÇA, A. C.; MALVEZZI, S. O conceito de resiliência aplicado ao trabalho nas organizações. Revista Interamericana de Psicologia, v.42, n.1, p.101-112, 2008. 
BERGAMINI, C. W. Psicologia aplicada à administração de empresas: psicologia do comportamento organizacional. 4. ed. São Paulo: Atlas, 2005.

BLACK, J. S.; MENDENHALL, M. The U-Curve adjustment hypothesis revisited: A review and theoretical framework. Journal of International Business Studies, v.22, n. 2, p.225-247, 1991.

CALIGIURI, P. M. Selecting expatriates for personality characteristics: a moderating effect of personality on the relationship between host national contact and cross-cultural adjustment. Management International Review, v.40, n.1, p.61-80, 2000.

CALIGIURI, P. M.; TARIQUE, I. Dynamic cross-cultural competencies and global leadership effectiveness. Journal of World Business, v.47, p.612-622, 2012.

CÂMARA BRASIL CHINA. Cultura. São Paulo, SP, 2017. Disponível em: <http:// http://www.camarabrasilchina.com.br/a-china/cultura >. Acesso em: 10 mar. 17.

CANTONI, F.; GIUSTINIANO, L. Developing organizational resilience via international mobility: a conceptual framework. Vita e Pensiero, v.106, p.1-42, 2015.

COLLIE, P.; KINDON, S.; LIU, J.; PODSIADLOWSKI, A. Mindful identity negotiations: The acculturation of young Assyrian women in New Zealand. International Journal of Intercultural Relations, v.34, p.208-220, 2010.

COUTU, D. L. How resilience works. Harvard Business Review. p.46-54, May, 2002.

DICORCIA, J. A.; TRONICK, E. Quotidian resilience: Exploring mechanisms that drive resilience from a perspective of everyday stress and coping. Neuroscience and Biobehavioral Reviews, v.35, p.1593-1602, 2011.

EDSTRÖM, A.; GALBRAITH, J.R. Transfer of managers as a coordination and control strategy in multinational organizations. Administrative Science Quarterly, v. 22, n. 2, p. 248-263, 1977.

ERIKSSON, P.; KOVALAINEN, A. Qualitative Methods in Business Research. London: Sage, 2008.

FONSECA, A. C. P. D. Comunicação intercultural em uma empresa transnacional: a visão dos brasileiros sobre sua comunicação com os norte-americanos. Cad. EBAPE.BR, v.9, n.4, art.9, p.1099-1121, Rio de Janeiro, Dez. 2011.

FREITAS, M. E. Multiculturalismo e expatriação nas organizações: vida do executivo expatriado, a festa vestida de riso ou de Choro. In: DAVEL, E.; VERGARA, S. C. (Org.). Gestão com pessoas e subjetividade. 4. ed., p. 261-274, São Paulo: Atlas, 2010.

FROESE, F. J.; PELTOKORPI, V. Cultural Distance and expatriate job satisfaction. International Journal of Intercultural Relations, v.35, p.49-60, 2011.

GALLON, S.; SCHEFFER, A. B. B. Expatriação: uma oportunidade de repensar a carreira. Revista Alcance Eletrônica, v.22, n.2, p.298-315, Abr./Jun., 2015.

GOLDSCHMIDT, C. C.; IRIGARAY, H. A. Resiliência: (Des)construindo O Constructo Sob a Ótica dos Gestores. In: ENCONTRO DE ESTUDOS ORGANIZACIONAIS DA ANPAD - EnEO. 9. Anais... Belo Horizonte: ANPAD, 2016.

GROTBERG, E. H. Novas tendências em resiliência. In: MELILLO, A.; OJEDA, E. N. S. Resiliência: descobrindo as próprias fortalezas. Porto Alegre: Artmed, 2005.

HOFSTEDE, G. Culturas e Organizações: compreender a nossa programação mental. Lisboa: Edições Silabo, 1991.

INFANTE, F. A resiliência como processo: uma revisão da literatura recente. In: MELILLO, A.; OJEDA, E. N. S. Resiliência: descobrindo as próprias fortalezas. Porto Alegre: Artmed, 2005.

LUTHAR, S. S.; LYMAN, E. L.; CROSSMAN, E. J. Resilience and Positive Psychology. In: LEWIS, M.; RUDOLPH, K. D. Handbook of Developmental Psychopathology. p.125-140, Springer Science+Business Media New York, 2014.

MACHADO, H. V.; HERNANDES, C. A. Alteridade, expatriação e trabalho: implicações para a gestão organizacional. Revista de Administração Contemporânea, v.8, n.3, p.53-73, Jul./Set., 2004. 
MASTEN, A. S. Resilience in children threatened by extreme adversity: Frameworks for research, practice, and translational synergy. Development and Psychopathology, v.23, p.493-506, 2011.

MASTEN, A. S.; CICCHETTI, D. Resilience in Development: Progress and Transformation. Developmental Psychopathology, v.4, n.6, p.1-63, 2016.

MINELLO, I. F. Resiliência e Insucesso Empresarial: o comportamento do empreendedor diante do fracasso nos negócios. Curitiba: Appris, 2014.

MINELLO, I. F.; SCHERER, L. A.; ALVES, L. C. Competências do empreendedor: Uma análise com empreendedores que vivenciaram o insucesso empresarial. Rev. de Negócios, v.17, n.4, p.74-90, 2012.

MORGAN, G. Imagens da organização. São Paulo: Atlas, 1996.

MOTT, M.; TEIXEIRA, M. L. M.; NAKASHIMA, C.; ARAÙJO, G. S. Sistematização da Literatura Internacional sobre Expatriados: um estudo bibliométrico com destaque para metodologia empregada em anos recentes. Revista Gestão \& Tecnologia, Pedro Leopoldo, v. 12, n. 2, p. 243-267, 2012.

MURITIBA, P. M.; ALBUQUERQUE, L. G. Características da gestão estratégica de pessoas para as organizações internacionalizadas. In: ALBUQUERQUE, L. G.; LEITE, N. P. (Org.) Gestão de pessoas: perspectivas estratégicas. p.154-163, São Paulo: Atlas, 2009.

MURITIBA, P.M.; MURITIBA, S.N.; ALBUQUERQUE, L.G.; BERTOIA, N.; FRENCH, J. L. International Strategy, Cultural Distance and Management Policies in Brazilian MNC. Journal Globalization, Competitiveness \& Governability, v.4, n.3, p.24-37, Sept./Dec., 2010.

NUNES, L. H.; VASCONCELOS, I. F. G.; JAUSSAUD, J. Expatriação de Executivos. São Paulo: Thomson Learning, 2008.

ORSI, A. Gestão internacional de pessoas: políticas de recompensas para expatriados por empresas brasileiras. Tese (Doutorado). Faculdade de Economia, Administração e Contabilidade da Universidade de São Paulo, São Paulo, 2010.

PIMENTEL, J. E. A. Empresas Brasileiras na China: estratégia e gestão. Dissertação (Mestrado). Faculdade de Economia, Administração e Contabilidade da Universidade de São Paulo, São Paulo, 2009.

RICHARDSON, R. J. Pesquisa Social: métodos e técnicas. 3. ed. São Paulo: Atlas, 2011.

RUTTER, M. Resilience as a dynamic concept. Development and Psychopathology, v.24, p.335-344, 2012.

SAMPIERI, R. H.; COLLADO, C. F.; LUCIO, P. B. Metodologia da Pesquisa. São Paulo: Mc Graw-Hill Interamericana Brasil Ltda, 2006.

SATO, L. A representação social do trabalho penoso. In: SPINK, M. G. 0 conhecimento no cotidiano: as representações sociais na perspectiva da psicologia social. São Paulo: Brasiliense, 1993.

SEERY, M. D.; HOLMAN, E. A.; SILVER, R. C. Whatever Does Not Kill Us: Cumulative Lifetime Adversity, Vulnerability, and Resilience. Journal of Personality and Social Psychology, v.99, n.6, p.1025-1041, 2010.

SHAFFER, M.A.; HARRISON, D. A.; GREGERSEN, H.; BLACK, J. S.; FERZANDI, L. A. You can take it with you: individual differences and expatriate effectiveness. Journal of Applied Psychology, v.91, n.1, p.109-125, 2006.

SILVA, N. B.; ORSI, A.; NAKATA, L. E. Análise da Produção Acadêmica sobre Gestão Internacional de Recursos Humanos entre 2001 e 2011. ReCaPe - Revista de Carreiras e Pessoas. São Paulo, v.03, n. 03, p. 50-60, 2013.

STEGER, T.; LANG, R.; GROEGER, F. Expatriates and the institutionalisation of HRM practices. Baltic Journal of Management, v.6, n.1 p.7-24, 2011.

STAHL, G. K.; CALIGIURI, P. The effectiveness of expatriate coping strategies: the moderating role of cultural distance, position level, and time on the international assignment. Journal of Applied Psychology, v.90, n.4. p.603-615, 2005.

VAN ERP, K. J.P.M.; GIEBELS, E.; VAN DER ZEE, K. I.; VAN DUIJN, M. A. J. Let it be: expatriate couples' adjustment and the upside of avoiding conflicts. Anxiety, Stress \& Coping: An International Journal, v.24, n.5, p.539-560, 2011. 
WANG, S.; TONG, W. T.; CHEN, G.; KIM, H. Expatriate Utilization and FDI Performance: The Mediating Role of Knowledge Transfer. Journal of Management, v.35, n.5, p.1181-1206, 2009.

ZWIELEWSKI, G.; TOLFO, S. R. Qualidade de vida no trabalho de profissionais expatriados para Índia e China. REAd - Revista Eletrônica de Administração, v. 22, n. 2, p. 510-542, 2016. 